\title{
Oleander and Datura Poisoning: An Update
}

\author{
Vijay V Pillay ${ }^{1}$, Anu Sasidharan ${ }^{2}$
}

\begin{abstract}
India has a very high incidence of poisoning. While most cases are due to chemicals or drugs or envenomation by venomous creatures, a significant proportion also results from consumption or exposure to toxic plants or plant parts or products. The exact nature of plant poisoning varies from region to region, but certain plants are almost ubiquitous in distribution, and among these, Oleander and Datura are the prime examples. These plants are commonly encountered in almost all parts of India. While one is a wild shrub (Datura) that proliferates in the countryside and by roadsides, and the other (Oleander) is a garden plant that features in many homes. Incidents of poisoning from these plants are therefore not uncommon and may be the result of accidental exposure or deliberate, suicidal ingestion of the toxic parts. An attempt has been made to review the management principles with regard to toxicity of these plants and survey the literature in order to highlight current concepts in the treatment of poisoning resulting from both plants.

Keywords: Cerbera, Datura, Nerium, Oleander, Plant poison, Thevetia.

Indian Journal of Critical Care Medicine (2019): 10.5005/jp-journals-10071-23302
\end{abstract}

\section{INTRODUCTION}

India being a tropical country is host to a rich and varied flora encompassing thousands of plants; and while most are nonpoisonous, a significant few possess toxic properties of varying degree. Cases of accidental poisoning relating to these plants due to mistaken identity or exploratory behavior among children are not infrequent, while deliberate consumption in the form of suicidal attempts are also reported. ${ }^{1}$ Some cases are related to the intake of herbal remedies and traditional medicines which contain toxic plant principles. In some western countries such as the United States, $5-10 \%$ of all human toxic exposures that get reported to the Poison Control Centres involve plants. ${ }^{2}$ In India, the overall percentage of plant poisoning ranges from $6 \%$ to $15 \%$, but if the same is taken in the context of the rural population alone, the percentage can be as high as $63 \% .^{3}$ Of the many species of poisonous plants in India, the toxic profiles of Oleander (a primarily cardiotoxic plant) and Datura (a primarily neurotoxic plant) will be reviewed in this paper.

\section{Oleander}

The two types of oleander commonly encountered in India are pink oleander and yellow oleander. Both are predominantly cardiotoxic. Most such cardiotoxic plants contain various cardiac glycosides which act in similar fashion. Some of these glycosides are useful in pharmacotherapeutics (e.g., digitalis). Table 1 lists common plants that contain cardiac glycosides. However, some cardiotoxic plants do not contain glycosides (e.g., aconite).

\section{Pink Oleander (Nerium oleander)}

This plant is also known by other common names such as white oleander, common oleander, rose laurel, rose bay, rosa francesca, laurier rose, and adelfa. It is a large evergreen ornamental shrub belonging to the family Apocynaceae, with long, lanceolate, leathery leaves and clusters of white or pink flowers. The leaves produce a clear, thick sap. In Indian traditional medicine, the roots and leaves are used to prepare decoctions that are said to be useful in the treatment of various skin conditions. The root is sometimes used as an abortifacient by rural people. Pink oleander is also a
${ }^{1}$ Department of Forensic Medicine and Toxicology, Poison Control Centre, Amrita School of Medicine, Amrita Vishwa Vidyapeetham, Kochi, Kerala, India

${ }^{2}$ Department of Forensic Medicine and Toxicology, Forensic Pathology Unit, Amrita School of Medicine, Amrita Vishwa Vidyapeetham, Kochi, Kerala, India

Corresponding Author: Vijay V Pillay, Department of Forensic Medicine and Toxicology, Poison Control Centre, Amrita School of Medicine, Amrita Vishwa Vidyapeetham, Kochi, Kerala, India, Phone: +91 9895282388, e-mail: toxicology@aims.amrita.edu

How to cite this article: Pillay VV, Sasidharan A. Oleander and Datura Poisoning: An Update. Indian J Crit Care Med 2019;23(Suppl 4):S250-S255. Source of support: Nil

Conflict of interest: None

popular ornamental plant that is grown in gardens as well as on the dividers of national and state highways across India.

All parts of the plant are poisonous, especially the leaves, stem, seeds, and root. The following active toxins are present-oleandrin, neriin, folinerin, rosagenin, and digitoxigenin. These are cardiac glycosides and have digoxin-like effects, acting by inhibiting the sodium-potassium adenosine triphosphatase (Na-K-ATPase) pump. ${ }^{3}$ Leaves also contain oxalates. $15 \mathrm{~g}$ of the root or 5-15 leaves can be fatal if consumed. "Taste" or exploratory ingestions are unlikely to result in serious toxicity, but substantial ingestion causes rapid onset of nausea, vomiting, and diarrhoea. ${ }^{5}$ In one case, numbness of tongue was reported immediately after consumption of oleander tea. ${ }^{6}$

Gastrointestinal (GI) manifestations are followed by cardiovascular features such as marked bradycardia with PR and QRS prolongation. Sinus arrest, varying degrees of atrioventricular (AV) block with dissociation, or escape rhythms may occur, including paroxysmal atrial tachycardia with AV block, junctional tachycardia, frequent ventricular ectopics, and bigeminy. Hypotension may occur. In one case, atrial fibrillation with nonspecific ST segment changes and intraventricular conduction delays were seen more than 12 hours after ingestion. ${ }^{7}$ In another case which involved 
Table 1: Plants containing cardiac glycosides

\begin{tabular}{lll}
\hline \multirow{2}{*}{ Family } & \multicolumn{2}{c}{ Representative example } \\
\cline { 2 - 3 } Apocynaceae & Botanical name & Common name \\
& $\begin{array}{l}\text { Cerbera thevetia or } \\
\text { Thevetia peruviana }\end{array}$ & Yellow oleander \\
& Nerium oleander & $\begin{array}{l}\text { Common or pink } \\
\text { oleander }\end{array}$ \\
& Strophanthus & Dogbane \\
Asclepiadaceae & Asclepias & Milkweed \\
Celastraceae & Calotropis & Crown flower \\
Cruciferae & Euonymus europaeus & Spindle tree \\
& Cheiranthus & Wall flower \\
Liliaceae & Erysimum & Wall flower \\
& Convallaria majalis & Lily of the valley \\
& Urginia maritima or & Squill \\
Ranunculaceae & Urginia indica & \\
Scrophulariaceae & Helleborus niger & Henbane \\
& Digitalis purpurea & Foxglove \\
& Digitalis lanata & Woolly foxglove \\
\hline
\end{tabular}

inhalation of smoke from a burning oleander plant, a middleaged patient suffered from sinus bradycardia (without AV block), severe dizziness, and vomiting. ${ }^{8}$ Decreased QRS-T interval, T-wave flattening/inversion, irregular ventricular rate, and increased PR interval, etc., have also been reported. Hyperkalemia is common in cases of severe poisoning as a result of blockade of the Na-K-ATPase pump-potassium shift from the intracellular to the extracellular space. This makes it a very useful marker of toxicity and thereby a rapidly available laboratory feature in severe cardiac glycoside poisoning. ${ }^{9}$

Delirium, lethargy, dizziness, drowsiness, and headache are other features of pink oleander poisoning. Occasionally there may be seizures followed by coma. Metabolic acidosis can occur. Rarely, blurred vision or alteration in color perception (classically xanthopsia) may also occur. Skin contact, particularly with the sap, may produce dermatitis.

Since the oleander-derived cardiac glycosides are cross reactive with the frequently used radioimmunoassay for digoxin, elevated levels may help the treating physician to confirm suspicion of poisoning. ${ }^{10}$ In one case, fluorescence polarization immunoassay for digoxin successfully detected the presence of oleander glycosides in blood. ${ }^{11}$ Thin-layer chromatography and fluorescence spectrophotometry can be used to identify oleander glycosides. High-performance liquid chromatography with or without mass spectrometry (MS) is more sensitive and conclusive. ${ }^{12}$

\section{Yellow Oleander (Thevetia peruviana, T. nerilfolia, Cerbera theVetia)}

Other common names for this plant include exile oleander, bastard oleander, be-still tree, lucky nut, and tiger apple. This plant is also an ornamental shrub (grows up to 30 feet in height) belonging to the family Apocynaceae, with yellowish funnel-shaped flowers and longish leaves (about $15 \mathrm{~cm}$ ) yielding a milky sap. The leaves are pointed in shape and have a dark green upper surface and lighter green undersides. The edges are often rolled. The fruit is diamond or clam shaped and has 2-4 seeds in the stony inner section. It is about half an inch in diameter, and the color is greenish, turning yellow when ripe, and may even appear blackish in later stages.
All the parts of this plant, especially the seeds and root are poisonous. The active toxins include thevetin $B$, cerberin, nerifolin, thevetin A, ruvoside, and peruvoside (in ascending order of toxicity). The usual fatal dose comprises $15-20 \mathrm{~g}$ of root or 8-10 seeds. In general, yellow oleander is more toxic than pink oleander.

As in the case of pink oleander, yellow oleander is also used in traditional Indian medicine. The bark contains cardenolides, which have been investigated as cytotoxic agents for the treatment of cancer. In the past, yellow oleander glycosides have been used in the treatment of heart failure and atrial fibrillation, but subsequently this was discontinued due to high toxicity. The seeds of this plant have been used in suicidal and homicidal cases. ${ }^{13}$

Toxicokinetics and toxic effects are similar to those encountered in pink oleander. The most commonly seen manifestations in poisoning include Gl distress, bradycardia with AV block, hypotension, lethargy, and dizziness. ${ }^{14}$ Convulsions, electrolyte disturbances, hypertension, and coma have been reported in severe poisoning. Mydriasis can occur. Numbness with a burning sensation of the mouth may develop initially on chewing the seeds. In one study of 300 yellow oleander seed ingestions with suicidal intent, $12 \%$ of the patients had palpitations, while $46 \%$ had some type of arrhythmia; sinus bradycardia was present in $49 \%$ of the patients, and ischemic electrocardiograph (ECG) changes were noted in 39\% of the patients. ${ }^{15}$ Subendocardial and perivascular hemorrhage with focal myocardial edema were found during autopsies of some of the patients who died. First-degree heart block was noted in one patient about 6 hours after the ingestion of yellow oleander seeds, with complete heart block occurring a little later. ${ }^{16}$ The sap of yellow oleander may cause blistering or dermatitis on contact. With regard to clinical diagnosis of poisoning, cardiac glycosides of this plant are best identified by radioimmunoassay.

In suspected cases of oleander poisoning (both types), cardiopulmonary resuscitation/resuscitation should be initiated immediately and continued for at least 1 hour as good outcomes have been reported on prolonged resuscitation. This must be followed by baseline ECG, electrolyte estimation, and 24-hour intensive care unit observation. Gastric lavage is of limited benefit due to the large size of plant parts in relation to the lavage tube. In fact, the procedure may worsen bradycardia secondary to vagal stimulation. Whole gut lavage is said to be more beneficial. Administration of activated charcoal $(50 \mathrm{~g}$ for adults; $1 \mathrm{~g} / \mathrm{kg}$ for children) is recommended for patients presenting to the emergency room (ER) within 4 hours of ingestion.

In all patients, the levels of urea, electrolytes, magnesium, and creatinine must be estimated. Hyperkalemia is quite common and careful/accurate estimation of serum potassium is one of the most important laboratory tests to be performed, in order to correlate with cardiotoxicity. ${ }^{17}$ Severe hyperkalemia $(>6.5 \mathrm{mEq} / \mathrm{L})$ is normally an indication for digoxin-specific antibody therapy. Additionally, consider treating hyperkalemia with intravenous (IV) dextrose and insulin, while antibody is obtained.

- Adults: insulin and dextrose: give 10 units of short-acting insulin (e.g., Actrapid) with $50 \mathrm{~mL}$ of $50 \%$ dextrose (or $100 \mathrm{~mL}$ of $20 \%$ dextrose) IV for over 5 minutes. If hyperkalemia is not improving, these doses may need to be repeated. Calcium salts can be given together with the insulin dextrose $-10 \mathrm{~mL}$ of $10 \%$ calcium chloride slow IV, with continuous cardiac monitoring. Alternatively, $10-20 \mathrm{~mL}$ of $10 \%$ calcium gluconate slow IV can be administered. This dose should be repeated in 5-10 minutes if no improvement in the ECG is reported. 
- Children (less than 12 years old): in case of evidence of ECG changes, with continuous cardiac monitoring, slowly give 0.1 $\mathrm{mL} / \mathrm{kg}$ body weight (max. $10 \mathrm{~mL}$ ) 10\% calcium chloride. Give nebulized salbutamol ( $2.5 \mathrm{mg}$ if younger than 2.5 years; $5 \mathrm{mg}$ if 2.5-7.5 years; $10 \mathrm{mg}$ if older than 7.5 years) and remeasure serum potassium and blood $\mathrm{pH}$. If serum potassium remains high and $\mathrm{pH}$ is 7.34 or less, give sodium bicarbonate $1-2 \mathrm{mmol} / \mathrm{kg}$ over 10 minutes and repeat until the $\mathrm{pH}$ is 7.35 or above-if serum potassium remains high at this $\mathrm{pH}$, give $5 \mathrm{~mL} / \mathrm{kg} 10 \%$ glucose and monitor the blood glucose concentrations. If the glucose concentrations are $>10 \mathrm{mmol} / \mathrm{L}$, and if serum potassium is not falling, commence an insulin infusion 0.05 units $/ \mathrm{kg} / \mathrm{hour}$ and titrate the rate according to the blood glucose concentration, which must be measured frequently. In all cases, administer calcium Resonium $1 \mathrm{~g} / \mathrm{kg}$ orally or rectally.

Perform a 12-lead ECG in all patients who require assessment. Repeat 12-lead ECGs are recommended, especially in symptomatic patients. Check cardiac rhythm, QRS duration, and QT interval.

- Atropine for sinus bradycardia and AV block: 1 mg IV; repeat in 3-5 minutes if asystolic cardiac arrest persists. Three milligram $(0.04 \mathrm{mg} / \mathrm{kg})$ IV is generally considered to be a fully vagolytic dose in most adults. Insertion of a pacemaker should be considered in those patients with severe bradycardia and/or slow ventricular rate due to second-degree AV block who fail to respond to atropine (and/or phenytoin).

- Antiarrhythmics: lignocaine is useful in the management of ventricular tachyarrhythmias, premature ventricular contractions (PVCs), and bigeminy.

Digoxin-specific antibodies (digoxin-specific Fab fragments) are the treatment of choice for severe bradyarrhythmias with hypotension unresponsive to atropine and life-threatening ventricular arrhythmias. ${ }^{18}$ Antidotal effect is usually seen within 15-30 minutes of administration. They are also the treatment of choice in managing severe hyperkalemia (Kgreater than $6.5 \mathrm{mEq} / \mathrm{L}$ ) secondary to acute cardiac glycoside overdose. Digoxin-specific antibody doses required in cardiac glycoside-containing plant poisoning are likely to be far larger than those used in digoxin poisoning. A dose of $10-20$ vials $(400-800 \mathrm{mg}$ ) may be required in severe cases. Repeated doses may be necessary. Additionally, consider treating hyperkalemia with IV dextrose and insulin while antibody is obtained. Digoxin-specific antibodies have been found to be effective in the management of arrhythmias in several cases, which rapidly restore sinus rhythm and revert bradycardia and hyperkalemia. ${ }^{19}$ Digoxin Fab fragments are indicated if the potassium concentration exceeds the upper limit of the normal range $(5 \mathrm{mEq} / \mathrm{L})$, in association with other severe symptoms. Even if the exact cause is uncertain as to whether oleander is the culprit in a given case, one study recommends the empiric administration of 10 vials of digoxin-specific Fab. ${ }^{20}$ However, serum potassium can drop steeply and must be monitored frequently for several hours post administration. This is especially likely to occur if Fab fragments have been given along with glucose, insulin, and bicarbonate. The latter combination therapy (glucose, insulin, and bicarbonate) must be tried only if Fab fragments are not available.

Certain steroid compounds such as spironolactone and pregnenolone $16 \mathrm{a}$-carbonitrile have been shown to decrease cardiac glycoside toxicity by increasing biliary excretion. Although not yet tried in humans, these agents could be tried as a treatment modality in both types of oleander poisoning. ${ }^{3}$
Hypotension is corrected by adequate fluid resuscitation with a crystalloid and brady- and tachyarrhythmias can be treated appropriately. Vasopressors or inotropes can be initiated in emergency through peripheral venous access.

If metabolic acidosis persists despite correction of hypoxia and adequate fluid resuscitation, consider correction with IV sodium bicarbonate. In adults, an initial dose of $50 \mathrm{mmol}$ may be given and repeated as necessary but guided by arterial blood gas monitoring [aim for a $\mathrm{pH}$ of 7.44 (hydrogen ion concentration 36$)]$. In children, use $8.4 \%$ sodium bicarbonate diluted in an equal volume of $5 \%$ glucose and give a "calculated" dose: dose (in $\mathrm{mmol})=$ desired change in base deficit (current target) $\times 0.3 \times$ weight of child up to a maximum of $50 \mathrm{mmol}$. Administer at a rate of $1 \mathrm{mmol} / \mathrm{minute}$. Recheck acid-base status after administration of sodium bicarbonate. For severe acidosis, large amounts of bicarbonate with repeated $\mathrm{pH}$ checking may ultimately be required to correct the metabolic acidosis. Monitor electrolytes since there is a risk of hypokalemia and possibly hypernatremia.

Hemodialysis or hemoperfusion is not likely to increase the elimination of cardiac glycosides as they have large volume of distribution in the body and are highly bound to protein. However, in the presence of renal failure, they may be beneficial for severe hyperkalemia/acidosis.

Accidental poisoning with regard to certain parts of this plant can occur in the form of "herbal tea" or "traditional medicine."21 Suicidal ingestion of various parts of these plants is not uncommon in India. ${ }^{17}$ Homicidal cases, though rare, have also been reported. A middle-aged man presented to the ER with a 2-month history of nausea, anorexia, colicky abdominal pain, vomiting, diarrhea, lethargy, confusion, dry mouth, dizziness, paresthesias, tremor, and episodes of slurred speech with blurred, yellowish vision. Police investigation later revealed that the wife was attempting to poison him using water boiled with roots of common oleander for making coffee over an 8-week period. ${ }^{22}$

\section{Datura}

This plant is also known by the following common names: Angel's Trumpet, Apple of Peru, Devil's Apple, Devil's Weed, Green Dragon, Jamestown Weed, Jimson Weed, Locoweed, Moon Lily, Stinkweed, and Thorn Apple. Common species comprises Datura stramonium, D. metel (Hindu Datura), and D. fastuosa.

This is a small shrub with a strong and somewhat unpleasant smell, belonging to the family Solanaceae which grows wild all over the Indian countryside. It grows to a height of 3-5 feet and has thick foliage of dark green ovate, pointed leaves, and large tubular (trumpet shaped) flowers which may be white (alba) or purple (niger). The fruit capsule is spherical with soft spines and contains up to 200 small (2-3 mm size) dark brown or black, reniform seeds, which bear a superficial resemblance to chilly seeds (Table 2). All parts of the plant, especially the seeds, are poisonous. The toxic principles (commonly referred to as belladonna alkaloids) include hyoscine (scopolamine), hyoscyamine, and traces of atropine. In decreasing order, the alkaloid content is generally greatest in the flowers, stem, fruit/seeds, leaves, and roots. One gram of seeds (approx. 125 seeds) contains $2.9 \mathrm{mg}$ atropine and $0.5 \mathrm{mg}$ scopolamine. ${ }^{23}$ The alkaloids inhibit the muscarinic effects of acetylcholine on the autonomic effectors innervated by postganglionic cholinergic nerves or on smooth muscles that do not contain cholinergic innervations. Central nervous system effects result from their central antimuscarinic actions, i.e., vagal 
Oleander and Datura Poisoning: An Update

Table 2: Differences between chilly and Datura seeds

\begin{tabular}{ll}
\hline Chilly seed & Datura seed \\
\hline Small & Large \\
Yellow & Brown \\
Rounded and smooth & Reniform and pitted \\
Pungent odur & Odorless \\
Pungent taste & Bitter taste \\
On section, the embryo is seen to curve & Embryo curves outward \\
inward toward the hilum & \\
\hline
\end{tabular}

Table 3: Medicinal uses of Datura alkaloids

\begin{tabular}{ll}
\hline Alkaloid & Uses \\
\hline Atropine & - Treatment of bradycardia, vagal syncope \\
& - Preanesthetic medication (for reducing salivation \\
& and bronchial secretions) \\
& - Antidote for organophosphates, carbamates, and \\
& certain mushrooms \\
& - Treatment of iridocyclitis, and for facilitating \\
& refractory procedures in children (local application \\
& as eye drops or ointment) \\
Hyoscine & - Antispasmodic \\
& - Aid to radiological and endoscopic examination of \\
& gastrointestinal tract \\
& - Preanesthetic medication \\
& Treatment of motion sickness (transdermal patch) \\
\hline
\end{tabular}

stimulation and decrease in heart rate. Datura alkaloids have various uses in modern medicine (Table 3).

Datura plant poisoning can lead to all the classical features of anticholinergic syndrome. Table 4 lists common agents causing such a toxidrome. Main signs and symptoms are often summarized in the classic phrase "blind as a bat, hot as a hare, dry as a bone, red as a beet, and mad as a wet hen," though it does not really reflect all the important manifestations. Instead, some toxicologists suggest that the signs and symptoms of Datura poisoning are better remembered as a series of D's: ${ }^{17}$

- Dryness of mouth, thirst, slurred speech

- Dysphagia

- Dilated pupils (with no reaction to light or accommodation)

- Diplopia

- Dry hot skin, with flushing, hyperpyrexia

- Drunken gait (ataxia), hyperreflexia, convulsions

- Delirium with hallucinations, agitation, amnesia, incoherence

- Dysuria, urinary retention, bladder distension

- Death, preceded by tachycardia, arrhythmias, coma, and respiratory depression

Sinus tachycardia and hyperthermia are common manifestations. Mydriasis and loss of accommodation for near vision are also common findings. Eye contact can cause marked dilation of the pupils and systemic features. This may be through the plant sap after direct handling of the plants or exposure to dried and ground materials processed alongside crops by combine harvesters (cornpickers eye). ${ }^{23}$ In one case, unilateral mydriasis occurred in seven patients following inadvertent ocular instillation of the sap from a Datura plant. Three of the patients also experienced ipsilateral cycloplegia. These manifestations resolved in all patients within a week postexposure. ${ }^{24}$ It is important to
Table 4: Anticholinergic agents

\begin{tabular}{|c|c|}
\hline Category & Examples \\
\hline Antidepressants (tricyclic) & $\begin{array}{l}\text { Amitryptiline, desipramine, doxepin, } \\
\text { imipramine, nortriptyline, etc. }\end{array}$ \\
\hline Antipsychotic drugs & Phenothiazines, butyrophenones \\
\hline Antihistamines & $\begin{array}{l}\text { Chlorpheniramine, diphenhydramine, } \\
\text { orphenadrine, promethazine }\end{array}$ \\
\hline Antiparkinsonian drugs & $\begin{array}{l}\text { Benztropine mesylate, biperiden, } \\
\text { ethopropazine, procyclidine, } \\
\text { trihexyphenidyl }\end{array}$ \\
\hline Antispasmodic drugs & $\begin{array}{l}\text { Methantheline bromide, propantheline } \\
\text { bromide }\end{array}$ \\
\hline Ophthalmic preparations & $\begin{array}{l}\text { Atropine ophthalmic solution, } \\
\text { cyclopentolate, tropicamide }\end{array}$ \\
\hline Other drugs & Methapyrilene \\
\hline Belladonna alkaloids & Atropine, scopolamine, hyoscyamine \\
\hline \multirow[t]{6}{*}{ Plant alkaloids } & Bittersweet (Solanum dulcamara) \\
\hline & Black henbane (Hyoscyamus niger) \\
\hline & Deadly nightshade (Atropa belladonna) \\
\hline & Jimson weed (Datura species) \\
\hline & $\begin{array}{l}\text { Jerusalem cherry (Solanum } \\
\text { pseudocapsicum) }\end{array}$ \\
\hline & $\begin{array}{l}\text { Potato leaves, tuber (Solanum } \\
\text { tuberosum) }\end{array}$ \\
\hline
\end{tabular}

remember that following direct eye contact, mydriasis may occur in only one eye.

Dry mouth and decreased GI motility with loss of bowel sounds are frequent symptoms of Datura poisoning. Swallowing becomes difficult, and speech may sound unintelligible. Urinary retention and bladder distention often occur and may necessitate catheterization. ${ }^{25}$ Hypertension has been reported in some cases. Tachypnea, with or without respiratory difficulty has been reported after ingestion of Datura seeds. ${ }^{26}$ In one case, a young boy developed respiratory failure secondary to acute respiratory distress syndrome after ingesting Datura seeds and died a few days later from refractory hypoxemia. ${ }^{27}$

The central nervous system (CNS) effects include ataxia, delirium, agitation, aggression, visual and auditory hallucinations, speech disorders, convulsions, myoclonus, and hypertonia. In one case, two teenaged males, who ingested a mixture of Datura extract and Coca Cola, presented with agitation about 1 hour later. Both recovered following supportive care. ${ }^{28}$ Toxic psychosis occurred from drinking tea containing Datura extract. ${ }^{29}$ Tonic-clonic seizures have also been reported following the ingestion of Datura tea concoction.

Other features include cardiac conduction abnormalities and arrhythmias, paralytic ileus, hyperglycemia, rash, and glaucoma. Abnormal liver and renal function and rhabdomyolysis have also been reported. Patients who are comatose may be hypothermic. In severe cases, initial CNS excitation gives way to CNS depression, coma, and circulatory and respiratory failure.

The usual fatal dose comprises 50-100 Datura seeds or 10-100 mg of atropine (commonly 50-60 mg). However, recovery has been recorded with more than $500 \mathrm{mg}$ of atropine. ${ }^{30}$ Signs and symptoms usually occur within 30-60 minutes and may continue for 24-48 hours due to delayed GI motility induced by the alkaloids.

As far as diagnosis is concerned, traces of atropine (as low as $10 \mathrm{ng} / \mathrm{mL}$ ) can be detected by gas chromatography-MS (GC-MS). 
However, little or no correlation has been observed between the dose of atropine, plasma concentration, and observed clinical effects. ${ }^{31}$ A simple bedside test would be to instill 2-3 drops of $1 \%$ pilocarpine in the eyes; if they do not constrict within 15-30 minutes of instillation, it is indicative of anticholinergic syndrome or atropine poisoning. ${ }^{17}$ Neuropathologically induced dilation can be effectively constricted by $1 \%$ pilocarpine.

The patient must be treated in a dark and quiet environment after ruling out all other neuropathological conditions, and vitals must be stabilized. Monitor ECG, pulse, and temperature continuously. Sinus tachycardia does not generally require treatment unless hemodynamic compromise develops. If therapy is required, a shortacting, cardioselective agent such as esmolol is generally preferred. Gut decontamination (lavage) followed by activated charcoal administration is recommended. Decreased GI motility is common and gastric decontamination may be useful even several hours after exposure. Datura seeds have been recovered from the stomach between 16 hours and 36 hours following ingestion. ${ }^{32}$ Intravenous fluids must be administered, keeping a close watch on intake and output and renal function. Bladder catheterization is usually necessary.

For agitation or delirium, adults can be sedated with IV diazepam $(0.1-0.3 \mathrm{mg} / \mathrm{kg})$; whereas in children, sedation is not recommended straightaway, and all attempts must be made to exclude other causes first. Mild to moderate hyperthermia may respond to conventional cooling measures. When rising body temperature exceeds $39^{\circ} \mathrm{C}$, core temperature monitoring should be considered (rectal probe) and urgent cooling measures should be employed according to local protocols. Sedation should be employed only in cases where it can be safely performed (diazepam $10-20 \mathrm{mg}$ in adults; $0.25 \mathrm{mg} / \mathrm{kg}$ in children). Dantrolene may be considered where there is muscular hyperactivity $(1 \mathrm{mg} / \mathrm{kg}$ IV to a maximum of $10 \mathrm{mg} / \mathrm{kg}$ ). In patients with hyperpyrexia, renal function and creatine kinase activity must be monitored. Adequate hydration and careful monitoring of urine output must be undertaken.

Physostigmine is the antidote of choice and should be administered if it is a case of serious poisoning with at least one of the following features: arrhythmias, hallucinations, severe hypertension, convulsions, or coma. ${ }^{17}$ For adults, 2 mg slow IV is recommended and can be repeated in 20 minutes; in children, $0.5 \mathrm{mg}$ slow IV, repeated at 5 minutes intervals can be given up to a maximum of $2 \mathrm{mg}$. Physostigmine is an effective but dangerous antidote and can lead to convulsions, asystole, hypotension, hypersalivation, and bradyarrhythmias, if administered without caution. Some investigators say that physostigmine should only be used as a diagnostic agent to distinguish anticholinergic delirium from other causes of altered mental status. Long-lasting reversal of anticholinergic signs and symptoms is generally not achieved in Datura poisoning because of the relatively short duration of action of physostigmine (20-60 minutes). It is a tertiary amine and easily passes the blood-brain barrier, unlike neostigmine and pyridostigmine which are quaternary ammonium compounds unable to traverse the blood-brain barrier and therefore are not effective in countering atropine-induced CNS toxicity. Pilocarpine is also ineffective.

Drugs to be avoided in the management of Datura poisoning include the following: antihistamines, phenothiazines, tricyclics, quinidine, disopyramide, procainamide, and morphine.

Hemodialysis or hemoperfusion will not aid in the removal of Datura alkaloids. However, hemodialysis may be required if acute renal failure develops or severe hyperkalemia is present.
Accidental poisoning may result from any one of the following:

- Mistaken identity involving capsicum seeds.

- Foraging children in the countryside chewing on the seeds (or other parts of the plant) out of curiosity.

- Therapeutic misadventures.

- Overenthusiastic use of atropine as an antidote for organophosphate or carbamate poisoning.

Suicidal cases are not infrequent, and even instances of murder have been reported from abroad (Dr Crippen case) as well as in India. ${ }^{33,34}$ Incidents of "stupefaction" by mixing Datura extract with food/drink, adulterating the tobacco in cigarettes, or even by exposing a victim to the fumes of incense (agarbathi) containing Datura extract are reported periodically from various parts of the country. This is resorted to by criminals for incapacitating a victim for the purpose of robbery or rape. Gullible bus or railway passengers are the usual victims who fall into the trap of accepting food, drink, or tobacco from unknown "friendly" strangers. Since Datura has mild hallucinogenic properties, the seeds, flowers, and leaves are sometimes ingested whole or in the form of preparations such as "tea" for a psychedelic experience. ${ }^{35,36}$

\section{References}

1. Khajja BS, Sharma M, Singh R, Mathur GK. Forensic study of Indian toxicological plants as botanical weapon (BW): a Review. J Environ Anal Toxicol 2011;1(3):112. DOI: 10.4172/2161-0525.1000112.

2. Nelson LS, Goldfrank LR. Plants. In: Nelson LS, Howland MA, Lewin NA, Smith SW, Goldfrank LR, Hoffman RS, ed. Goldfrank's Toxicologic Emergencies, 11th ed., USA: McGraw-Hill Education; 2019.

3. Pillay VV. Modern Medical Toxicology, 4th ed., New Delhi: Jaypee Brothers Medical Publishers; 2013.

4. Frohne D, Pfander HJ. Poisonous Plants, 2nd ed., Stuttgart, USA: Manson Publishing; 2005.

5. Slaughter RJ, Beasley DMG, Lambie BS, Wilkins GT, Schep LJ. Poisonous plants in New Zealand: a review of those most commonly enquired about to the National Poisons Centre. N Z Med J 2012;125(1367): 87-118.

6. Haynes BE, Bessen HA, Wightman WD. Oleander tea: herbal draught of death. Ann Emerg Med 1985;14(4):350-353. DOI: 10.1016/S01960644(85)80103-7.

7. Driggers DA, Solbrig K, Steiner JF, Swedberg J, Jewell GS. Acute oleander poisoning. West J Med 1989;151(6):660-662.

8. Khasigian P, Everson G, Bellinghausen R. Poisoning following oleander smoke inhalation. J Toxicol Clin Toxicol 1998;36:456-457.

9. Alexandre J, Foucalt A, Coutance G, Scanu P, Milliez P. Digitalis intoxication induced by an acute accidental poisoning by lily of the valley. Circulation 2012;125(8):1053-1055. DOI: 10.1161/ CIRCULATIONAHA.111.044628.

10. Roberts DM, Gallapatthy G, Dunuwille A, Chan BS. Pharmacological treatment of cardiac glycoside poisoning. $\mathrm{Br} J$ Clin Pharmacol 2016;81(3):488-495. DOI: 10.1111/bcp.12814.

11. Dasgupta A, Emerson L. Neutralization of cardiac toxins oleandrin, oleandrigenin, bufalin and cinobufotalin by digibind: monitoring the effect by measuring free digitoxin concentrations. Life Sci 1998;63(9):781-788. DOI: 10.1016/s0024-3205(98)00333-6.

12. Tor ER, Filigenzi MS, Puschner B. Determination of oleandrin in tissues and biological fluids by liquid chromatography-electrospray tandem mass spectrometry. J Agric Food Chem 2005;53(11):4322-4325. DOI: 10.1021/jf050201s.

13. de Silva HA, Fonseka MM, Parameswaran A, Alahakone DG, Ratnatilake GA, Gunatilake SB, et al. Multiple-dose activated charcoal for treatment of yellow oleander poisoning: a singleblind, randomised, placebo-controlled trial. Lancet 2003;361(9373): 1935-1938. DOI: 10.1016/s0140-6736(03)13581-7. 
14. Dwivedi S, Rajpal S, Narang S. Cardiotoxic manifestations of yellow oleander (Thevetia nerifolia) poisoning and its treatment: a case report. Indian Heart J 2006;58(6):450-451.

15. Bose TK, Basu RK, Biswas B. Cardiovascular effects of yellow oleander ingestion. J Indian Med Assoc 1999;97(10):407-410.

16. Ahlawat SK, Agarwal AK, Wadhwa S. Rare poisoning with Cerbera thevetia (yellow oleander): a report of three cases. Trop Doc 1994;24(1):37-38. DOI: 10.1177/004947559402400123.

17. Pillay VV. Comprehensive Medical Toxicology, 3rd ed., Hyderabad: Paras Medical Publisher; 2018.

18. Bateman DN. Digoxin-specific antibody fragments: how much and when? Toxicol Rev 2004;23(3):135-143. DOI: 10.2165/00139709200423030-00001.

19. Eddleston M, Rajapakse S, Rajakanthan, Jayalath S, Sjöström L, Santharaj W, et al. Anti-digoxin Fab fragments in cardiotoxicity induced by ingestion of yellow oleander: a randomised controlled trial. Lancet 2000;355(9208):967-972. DOI: 10.1016/s0140-6736(00)90014-x.

20. Barrueto Jr F, Jortani SA, Valdes Jr R, Hoffman RS, Nelson LS. Cardioactive steroid poisoning from an herbal cleansing preparation. Ann Emerg Med 2003;41(3):396-399. DOI: 10.1067/mem.2003.89.

21. Lin CC, Yang CC, Phua DH, Deng JF, Lu LH. An outbreak of foxglove leaf poisoning. J Chin Med Assoc 2010;73(2):97-100. DOI: 10.1016/ S1726-4901(10)70009-5.

22. La Couteur DG, Fisher AA. Chronic and criminal administration of Nerium oleander. J Toxicol Clin Toxicol 2002;40(4):523-524.

23. KrenzelokEP. Aspects of Datura poisoning and treatment. Clin Toxicol (Phila) 2010;48(2):104-110. DOI: 10.3109/15563651003630672.

24. Andreola B, Piovan A, Da Dalt L, Filippini R, Cappelletti E. Unilateral mydriasis due to Angel's trumpet. Clin Toxicol (Phila) 2008;46(4): 329-331. DOI: 10.1080/15563650701378720.
25. Isbister GK, Oakley P, Dawson AH, Whyte IM. Presumed Angel's trumpet (Brugmansia) poisoning: clinical effects and epidemiology. Emerg Med 2003;15(4):376-382. DOI: 10.1046/j.1442-2026.2003.00477.x.

26. Vanderhoff BT, Mosser KH. Jimson weed toxicity: management of anticholinergic plant ingestion. Am Fam Physician 1992;46(2):526-530.

27. Thabet $H$, Brahml N, Amamou M, Ben Salah N, Hédhili A, Yacoub M. Datura stramonium poisonings in humans. Vet Human Toxicol 1999;41(5):320-321.

28. Francis PD, Clarke CF. Angel trumpet lily poisoning in five adolescents: clinical findings and management. J Paediatr Child Health 1999;35(1):93-95. DOI: 10.1046/j.1440-1754.1999.00328.x.

29. Boumba VA, Mitselou A, Vougiouklakis T. Fatal poisoning from ingestion of Datura stramonium seeds. Vet Hum Toxicol 2004;46(2):81-82.

30. Ellenhorn MJ, Schonwald S, Ordog G, Wasserberger J. Ellenhorn's Medical Toxicology: Diagnosis and Treatment of Human Poisoning, 2nd ed., Baltimore, USA: Williams and Wilkins; 1997.

31. Berghem L, Bergman U, Schildt B, et al. Plasma atropine concentrations determined by radioimmunoassay after single-dose i.v. and i.m. administration. Br J Anaesth 1980;52(6):597-601. DOI: 10.1093/ bja/52.6.597.

32. Levy R. Letter: Jimson weed poisoning. Ann Int Med 1976;84(2):223.

33. Nash JR. World Encyclopedia of 20th Century Murder. New York: Paragon House; 1992.

34. Jani CB, Pataliya AH, Gupta BD, Dutta RG. Homicidal Datura poisoning: "Moksha by prashad"? J Indian Acad Forensic Med 2000;23:32-33.

35. Clark JD. The roadside high: Jimson weed toxicity. Air Med J 2005;24(6):234-237. DOI: 10.1016/j.amj.2005.08.007.

36. Spina SP, Taddei A. Teenagers with Jimson weed (Datura stramonium) poisoning. CJEM 2007;9(6):467-468. DOI: 10.1017/s1481803500015530. 